\title{
Regulation and control of radionuclide contents in foods in the Russian federation
}

\author{
N. K. Shandala, N. Ya. Novikova, A. V. Titov, E. G. Metlyaev \\ \& A. A. Filonova \\ FGU - Burnasyan Federal Medical Biophysical Centre of Federal \\ Medical-Biological Agency of the Russian Federation, Russia
}

\begin{abstract}
To restrict radiation exposure to the population of Russia due to radionuclide ingestion via foods produced from agricultural raw material cultivated in Russia or imported from other states, Permissible Levels (PL) of ${ }^{90} \mathrm{Sr}$ and ${ }^{137} \mathrm{Cs}$ specific activities have been developed. The regulations comply with requirements of national Radiation Safety Standards (NRB-99), international recommendations for limitation of the public exposure under conditions of long-term radiation exposure and take into account the special features of food contamination generation in Russia. PL have been developed under condition of non-exceeding of $1 \mathrm{mSv}$ annual internal dose to the public due to food intake. The levels developed for more than 140 kinds of foods have been included into the regulative document "Hygienic requirements of safety and food significance of foodstuffs" (SanPiN 2.3.2.1078-01) and are obligatory in Russia for national and imported foods.
\end{abstract}

Keywords: permissible levels, effective dose, public, critical group, foodstuffs.

\section{Introduction}

The radiation situation in Russia at the end of the twentieth century is specified by the presence of some areas and river environment contaminated with longlived radionuclides (mainly ${ }^{137} \mathrm{Cs}$ and ${ }^{90} \mathrm{Sr}$ ) due to radiation accidents, many-year activity of nuclear industry and tests of nuclear weapons. They include southwest regions contaminated with emergency fallout of the Chernobyl NPP; the area of southern Urals contaminated following the accident at the "Mayak" facility, local and regional contaminations of Altai and Far North areas, as well as river 
systems of Urals and Siberia. The majority of these territories are used to produce agricultural and meat and dairy production.

Radiation monitoring of the public doses due to ingestional intake of ${ }^{137} \mathrm{Cs}$ and ${ }^{90} \mathrm{Sr}$ via foodstuffs is one of the main requirements of radiation safety assurance of the population of the state. It assumes control inspections of food samples within the system of the state sanitary and epidemiological service in order to determine radionuclide contents in those samples.

In the light of above-mentioned circumstances, radioactive contamination of foods produced in Russia with ${ }^{137} \mathrm{Cs}$ and ${ }^{90} \mathrm{Sr}$ vary over the wide range.

To limit internal exposure to the public of Russia, development is necessary of some special hygienic regulations on permissible levels of ${ }^{90} \mathrm{Sr}$ and ${ }^{137} \mathrm{Cs}$ specific activities in foodstuffs.

Firstly, such kind of regulations has been developed in middle 1990s and included in the sanitary rules [1].

Over five-year period of this document existence, a number of theoretical and practical challenges have been accumulated concerning observation and compliance with its requirements on the following aspects:

- The frame of food ration of the population in Russia changed.

- New radiation safety standards [2] have been introduced, establishing the critical group (children of 12-17) for ingestional intake of ${ }^{90} \mathrm{Sr}$.

- Additional materials on radionuclide migration from soil into foodstuffs have been received.

- Trends in international radiation and hygienic regulation changed because of issue of the ICP publication in 2000 [3].

- Contradictions occurred in the system of the food regulation established in Russia, Belarus and Ukraine.

These circumstances required amendments in the food contamination regulation.

\section{The conception of radioactive substances regulation in foodstuffs}

The Conception of radioactive substances regulation in foodstuffs is as follows:

- Internal dose due to intake of biologically significant radionuclides ${ }^{90} \mathrm{Sr}$ and ${ }^{137} \mathrm{Cs}$ via food must not be higher than $1 \mathrm{mSv} / \mathrm{a}$ - the level of intervention exclusion with respect to the foodstuffs distributed via the trade network.

- For foods of low intake (wild berries, mushrooms, tea) it is accepted that dose due to their intake is out of $1 \mathrm{mSv} / \mathrm{a}$ dose quota and it must not be higher than $1 \%$ for the particular foodstuff.

- The regulations must cause release of the significant part of contaminated areas from the agricultural cycle (i.e., social and economic damage due to food quality inspection and subsequent food loss must be reasonably minimized). 
With the purpose of operational control of the dose criteria compliance, permissible levels have been established in a form of ${ }^{90} \mathrm{Sr}$ and ${ }^{137} \mathrm{Cs}$ specific activities in foodstuffs (PSA).

In the course of the PSA establishment, food rations of the public from different Russian regions were being analyzed, potential range of foods contamination has being assessed taking into account the actual radionuclide contents in soil and typical partial contributions of the particular components of the ration into strontium and cesium intake. The volume of foods production with different ${ }^{90} \mathrm{Sr}$ and ${ }^{137} \mathrm{Cs}$ specific activities was being evaluated for the most contaminated regions and potential economic damage due to food quality inspection was being predicted in terms of radiation indexes. Such kind of data used to minimize the economic damage served as a basis for expert determination of some special quotas on the partial contributions into dose induced by dairy and meat products intake.

To reach unification in the state system of foods classification and control, the list of foodstuffs, for which PSA have been established, corresponds to the listing used for regulation of chemical and biological substances, microorganisms and other biological organisms hazardous for health of the current and future generations.

Finally, the levels have been developed for more than 140 types of foodstuffs, the principal of which are listed in Table 1.

Table 1: $\quad$ Permissible specific activities of ${ }^{90} \mathrm{Sr}$ and ${ }^{137} \mathrm{Cs}$ in foodstuffs.

\begin{tabular}{|c|c|c|}
\hline \multirow{2}{*}{ Group of foodstuffs } & \multicolumn{2}{|c|}{ Permissible levels, $\mathrm{Bq} / \mathrm{kg}[1]$} \\
\cline { 2 - 3 } & ${ }^{137} \mathrm{Cs}$ & ${ }^{90} \mathrm{Sr}$ \\
\hline Bread and cereal products & 40 & 20 \\
\hline Bread-stuffs, pasta & 60 & 30 \\
\hline Milk and dairy & 100 & 25 \\
\hline Butter & 200 & 60 \\
\hline Potato & 120 & 40 \\
\hline Vegetables and melons & 120 & 40 \\
\hline Meat and meat products & 160 & 50 \\
\hline Fish and fish products & 130 & 100 \\
\hline Fruits and berries & 40 & 30 \\
\hline Wild berries & 160 & 60 \\
\hline Tea & 400 & 200 \\
\hline
\end{tabular}

\section{Control of the food compliance with the requirements of the regulations established}

Compliance of foods with the regulation established is being defined by the index taking into account total ${ }^{90} \mathrm{Sr}$ and ${ }^{137} \mathrm{Cs}$ contents in the foodstuff 


$$
\frac{{ }^{A} C S}{P S A_{C S}}+\frac{A_{S r}}{P S A_{S r}} \leq 1
$$

where $\mathrm{A}_{\mathrm{Cs}}$ - specific activity of Cs;

$\mathrm{A}_{\mathrm{Sr}}$ - specific activity of $\mathrm{Sr}$;

$\mathrm{PSA}_{\mathrm{Cs}}$ - permissible specific activity of Cs;

$\mathrm{PSA}_{\mathrm{Sr}}$ - permissible specific activity of Sr.

In the course of laboratory tests aimed at confirmation of the food compliance with the established regulation, the compliance index " $\mathrm{B}$ " is used and uncertainty of its determination $\Delta \mathrm{B}$. Their values are being calculated in terms of ${ }^{90} \mathrm{Sr}$ and ${ }^{137} \mathrm{Cs}$ specific activity measurements in a sample:

$$
B=\frac{{ }_{C S}}{P S A_{C s}}+\frac{A_{S r}}{P S A_{S r}} \quad \Delta B=\sqrt{\frac{\Delta A_{C s}}{P S A_{C s}}+\frac{\Delta A_{S r}}{P S A_{S r}}}
$$

Foodstuffs are recognized as surely complied with the regulations, if:

$$
B+\Delta B \leq 1
$$

\section{Conclusion}

The regulations developed and included in the sanitary rules "Hygienic Requirements of Safety and Food Significance of Foodstuffs" (SanPiN 2.3.2.1078-01) [4]:

- Surely guarantee the public safety in terms of the radiation factor and do not contradict with the optimization principle;

- Comply with the IAEA proposals on the criteria of ${ }^{137} \mathrm{Cs}$ and ${ }^{90} \mathrm{Sr}$ specific activity in foodstuffs distributed within international trade network;

- Permit to eliminate uncertainties in inter-territorial exchange between three states - Russia, Belarus and Ukraine;

- Permit to refuse using of emergency temporary permissible levels established previously at some territories.

Recent investigations demonstrated that real levels of ${ }^{90} \mathrm{Sr}$ or ${ }^{137} \mathrm{Cs}$ contents in the prime foodstuffs in Russia, excluding for areas of emergency contamination, were equal to quotas of percentage of the regulations. Excess ${ }^{137} \mathrm{Cs}$ and ${ }^{90} \mathrm{Sr}$ contents (less $1 \%$ of inspected samples) were registered, mainly, in dairy and milk produced within the private husbandries and in mushrooms and berries collected in two regions - Bryansk and Kaluga. 


\section{References}

[1] Hygienic requirements of safety and food significance of foodstuffs. Sanitary-epidemiological rules and norms. SanPiN 2.3.2.560-96. M. FSUE "InterSEN", 168 p, 1996.

[2] Radiation Safety Standards. NRB-99. Hygienic norms SP 2.6.1.758-99, Ministry of Health of Russia, 116 p. 1999.

[3] ICRP 82 "Protection of the Public in Situations of Prolonged Radiation Exposure", 41 p, 1999.

[4] Hygienic requirements for safety and food significance of foodstuffs. Sanitary-epidemiological rules and norms. SanPiN 2.3.2.1078-01. - M. FSUE “InterSEN”, 168 p, 2002. 